تنمية التذوق الفني باستخدام المستودع الرقمي عبر الإنترنت

إعلاد

د. عبير عبد الهه |الهندلركي

مجلة بحوث التربية النوعية ـ جامعة المنصورة

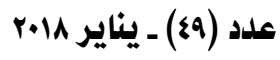




\title{
تنـية التذوق الفني باستخدام المستودع الرقمي عبر الإنترنت
}

\author{
إعداد

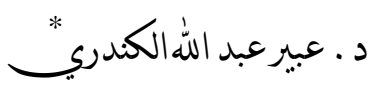

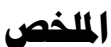

منظومة الحوسبة السحابية Cloud Computing System كغيرها من التقنيات

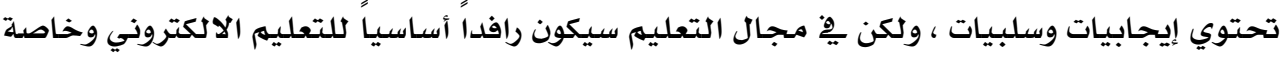

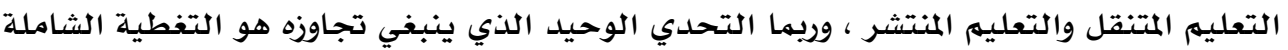

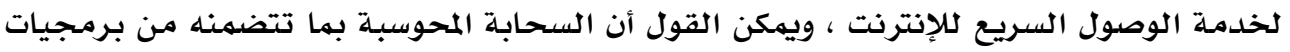

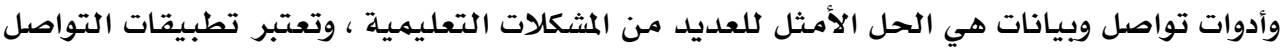

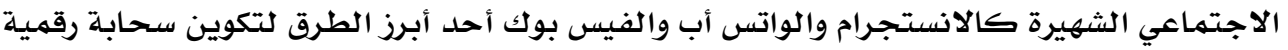

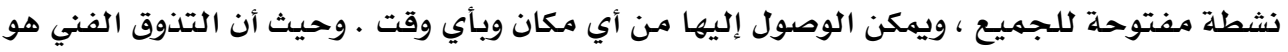

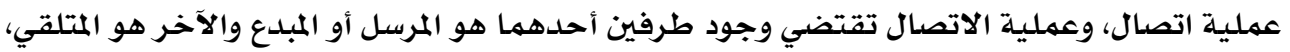

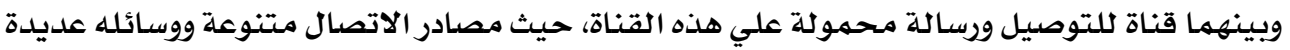

$$
\text { وأساليبه كثيرة . }
$$

وتكمن أهمية البحث الحالي يِّ تنمية التواصل المجتمعي بين الطالبات والمسؤولين التربويين .

• يساهم مِّْ تأكيد أهمية التعلم عن بعد Distance Learning أو التعلهم الذاتي Self Learning • يعد البحث مدخلاً جديدًا لتنمية التذوق الفني والرؤية الجمالية للفن عن طريق وسائط

$$
\text { تعليمية غير تقليدية. }
$$

ويهدف البحث الي معرفة أثر برامج التواصل الاجتماعي والمستودعات الرقمية علي التئي

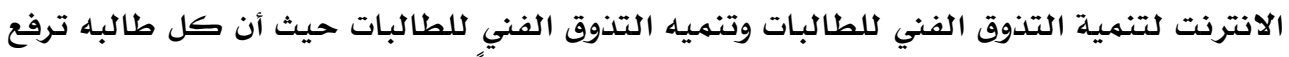

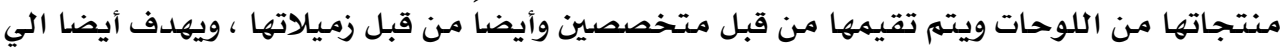

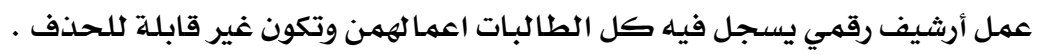
عينة البحث تم تطبيق البحث علي طالبات الصف التاسع بمدرسـة مشرف المتوسطة للبنات

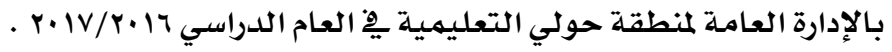


وكانت من أهم نتائج البحث ارتفاع المستوي الفني للوحات المعروضة ، تزايد أعداد اللوحات

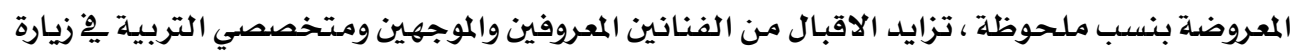

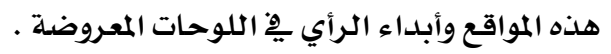
الكلمات المفتاحية : المستودع الرقهي ، برامج التواصل الاجتماعي ، التذوق الفني .

مقدهمة:

العمل الفني رسالة ذات سمة خاصدة موجهة من الفنان الإنسان الفرد إلي الآخر ، فهو

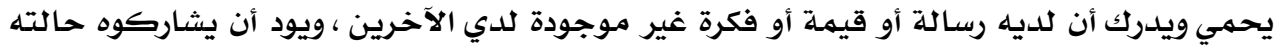

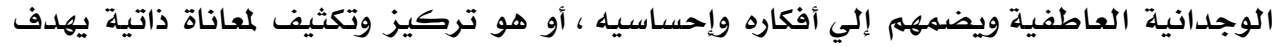

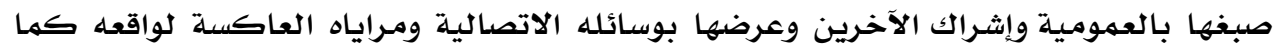

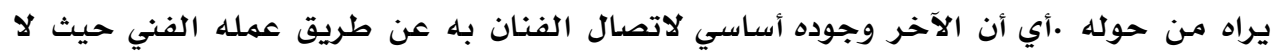

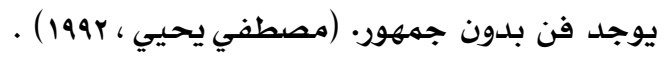
ويعرف مونرو Monroeالفن بأنه كل نشاط يتضهمن الفنون البصرية والموسيقية

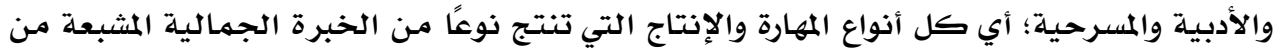

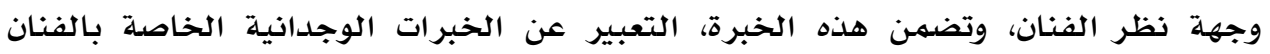
وتوصيلها.

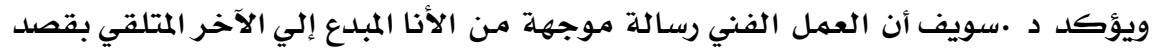

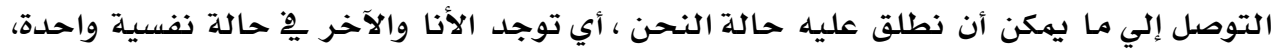

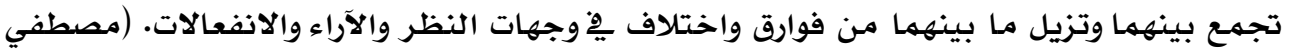

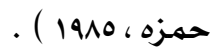
وعليه فأن الصور الفنية التي أبدعها الإنسان خلال رحلة البشرية تمثل وعاءً للتجربة

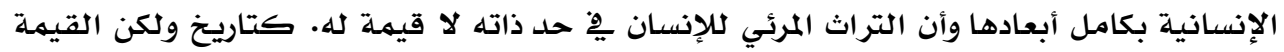

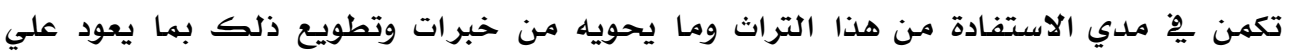

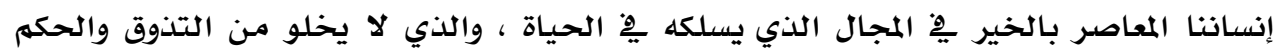

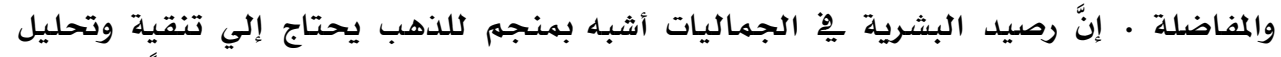

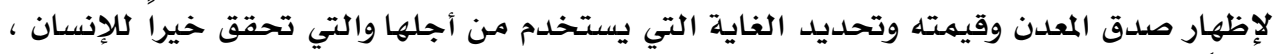

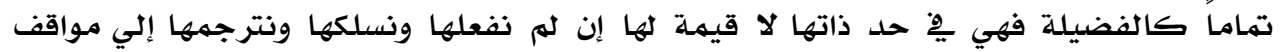

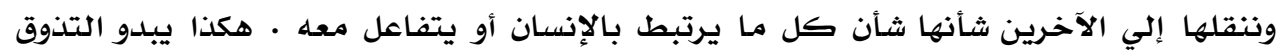

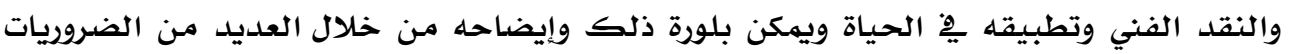

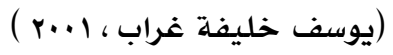




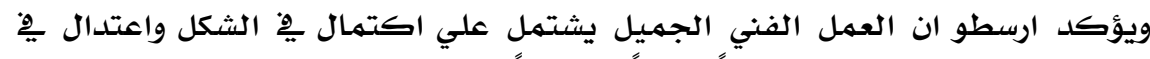

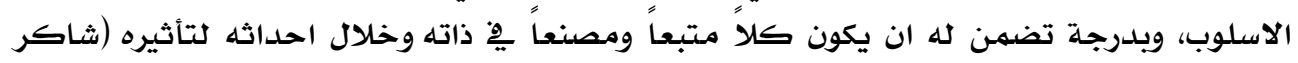

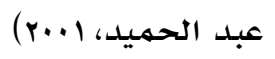

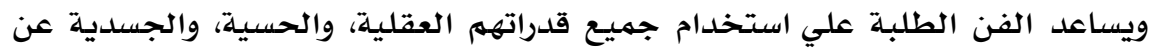

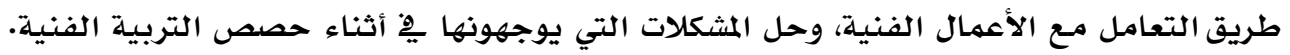

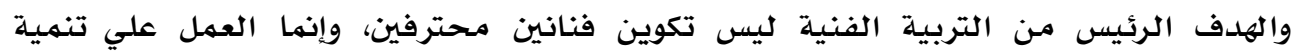

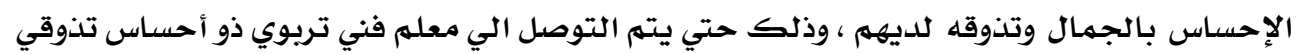

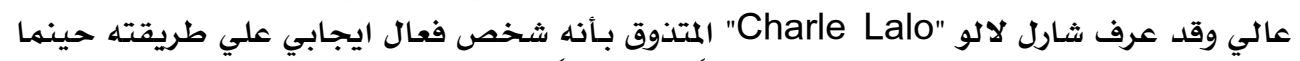

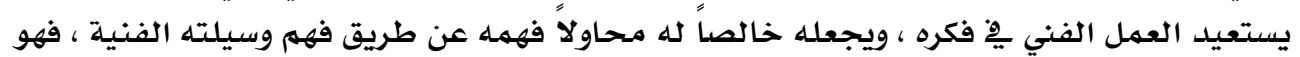

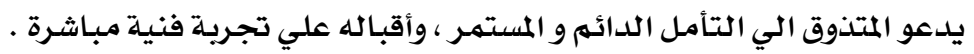
حيث أن التذوق الفني هو عملية اتصال، وعملية الاتصال، تقتضي وجود طرفين احدهما

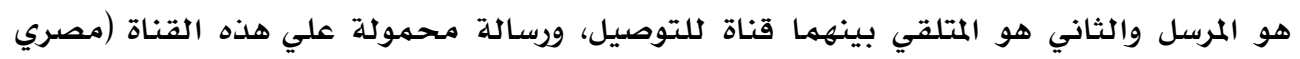

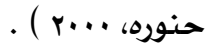

ويعرف ايضاً بأنه :عملية محاولة التعرف علي الأعمال الفنية وفهم أبعادها والكشف والفي

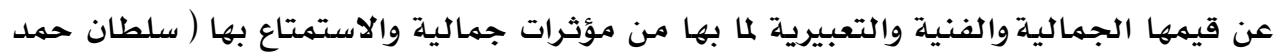

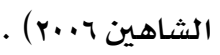

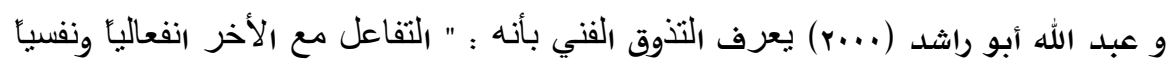

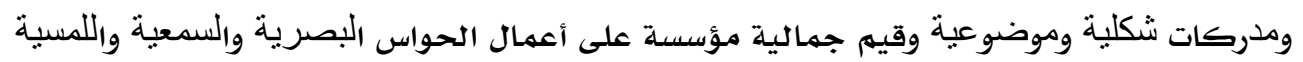

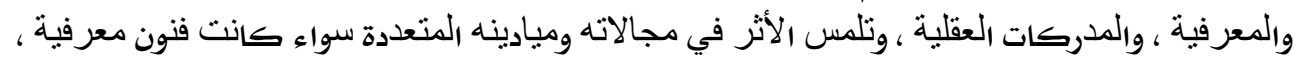

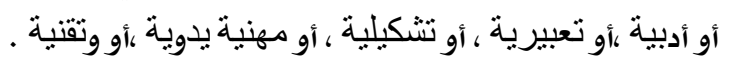

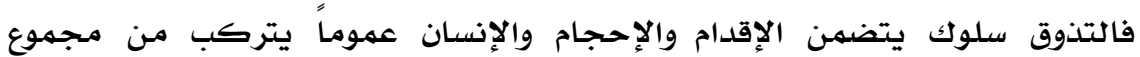

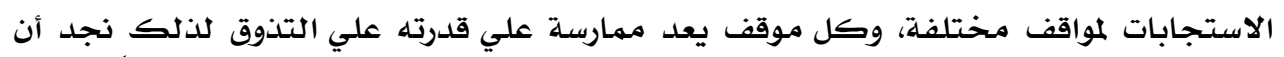
أولي وظائف التربية تكوين المعايير السليمة للتذوق، وتدريب المتعلهم علي تطبيقها عملياً ليرضي فئي

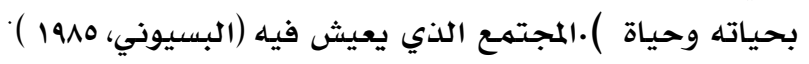

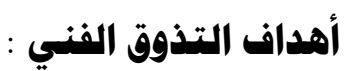
و يهدف التذوق الفني إلي تحقيق عدد من الأسس يذكرها كل من محمد حمدي

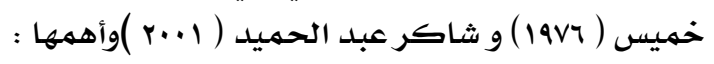

• تجنب التوتر الطبيعي لجميع أشكال الإدراك والإحساس وما يتصل بتناول الجماليات.

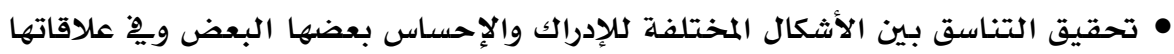
بالبيئة وهو ما ينعكس أثره علي الإنسان. • التعبير عن الإحساس بصيغة مانعكس أفره علي الانسان للنقل جماليا. 
• التعبير بصلير بصيغة قابلة للنقل عن أشكال الخبرة الكلية التي قد تظل لا شعوريـة جزئيا أو

ه التعبير عن منظومات جمالية جديدة للارتقاء بشكل الحياة فِ كافة مدخلاتها .

• التعبير عن الفكر الاستاطيقي بالصيغة المطلوبة .

• مححاولة للبحث عن استراتيجية عربية إسلامية جديدة للمفاهيه المستندة علي العقيدة في

$$
\text { مجسال دراسـة الجماليـات. }
$$

• محاولة لتأصيل جماليات الإبداع العربي الإسلامي.

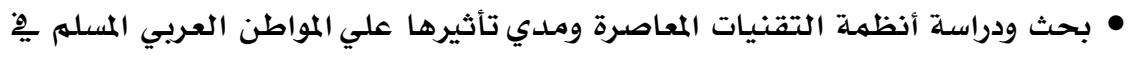

$$
\text { المجتمعات البكر. }
$$

• مححاولة لحفظ وصيانة الرموز الحضاريية العربية الإسلامية من متغيرات قد يحدثها الغزو

$$
\text { الثقايِّ لإذابة جماليات الفن العري الإسلامي. }
$$

• تحلديد معالم القيم الجمالية لدي الإنسان العريبي المسلهم.

• تطوير أنظمة السلوكيات يِ إطار جمالي يتفق مـ العقيدة الإسلامية.

لذلك يهر المتذوق بهـرحلتين رئيستين: وهما مـرحلة البحث والمعاناة (Inquiring)و

مرحلة الاكتساب (lcrquiring).

يْ المرحلة الاولى: يزاول التلميذ انواعا مختلفة من النشاط تتضمن بطريق غير مباشر

عامل التذوق كجزء مـن مقوماتها، ولذلك إذا مـا تمكن المعلم أن يجعل تلميذه يعي هذا العامل

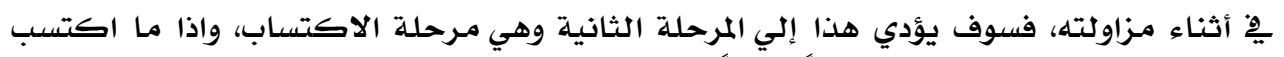

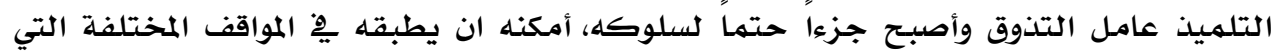
سيجابهها يخ المستقبل •وعند ذلك يتضح هذا العامل ويتسع مجاله، ويصبح احد الأركان المميزة لشخصيته يخ كل تصرفاتها. أي ان المرحلتين تنتهيان نتيجة هامـة نطلق عليها التعميه ومعناه تطبيق ويستمد المتعلم يِ موقف معين علي سـائر المواقف التي يجابها

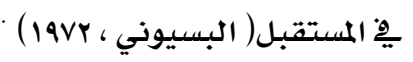

آلية التثذوق الفندي

ان التذوق الفني يدرك مـن قبل الانسـان من خلال اريـع نواحي اسـاسية تفسر عناصر التشكيل الفني والعلاقات الجمالية والعلاقات التعبيريـة والشكل المضهون والأداء والتقنية وهي

كما يلي: (نضال الربيعي، ب...r)

• الناحية الأولي : ( النتاج) ويركز علي إيجاد شيء بصيغة ما يترك اثراً يهكن إدراكه . • الناحية الثانية : ( النتاج وعلاقته بالمحيط )يهتم بالقيمة المعطاة لذلك النتاج بعدئ خروجه

$$
\text { إلي العاله. }
$$

• الناحية الثاثثة : (الأفعال الفكريـة) يهتم بـالأفعال السـابقة المؤدية إلي حصول النتاج. 
• الناحية الرابعة: (الأفراد وعلاقتهم بالمحيط ) :يهتم بهن يقوم بهذه الأفعال المؤدية إلي

النتاج

\section{عناصر التذوق الفني :}

• ترتكز عملية التذوق الفني على عدة عناصر أساسية ، حتى تكتمل حلقة التذوق الفني ، وقد ذكرها

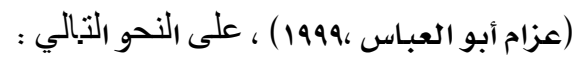

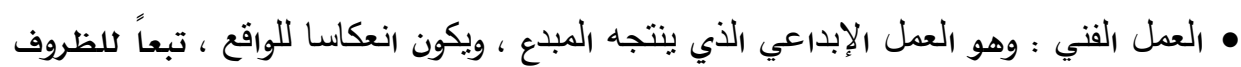

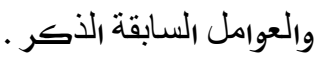

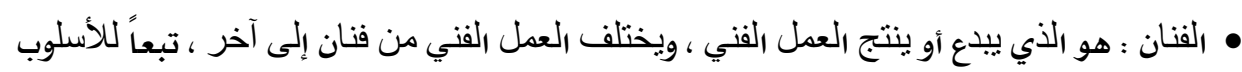

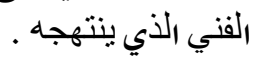

المتذوق : هو إنسان يستمتع بعمل فني معين ويتعاطف معه، وهذه الاستجابة تكون استجابة جمالية

$$
\text { شعورية . }
$$

• الناقد : هو شخص يملك ثقافة فنية عالية ، وله قدرة على دراسة وتحليل ، ووصف العمل الفني ،

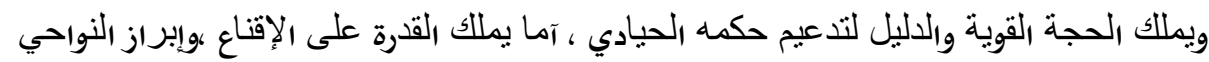

$$
\text { الإيجابية والسلبية في العمل الفني للفنان . }
$$

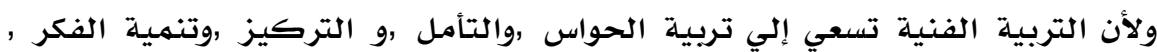

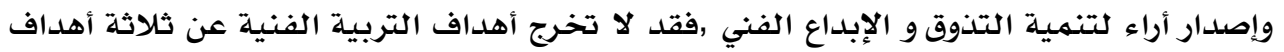

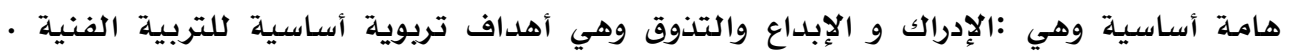

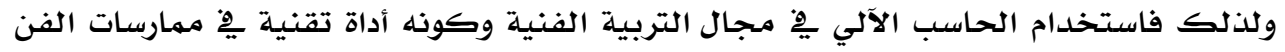

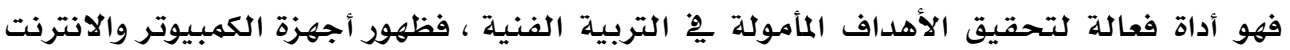

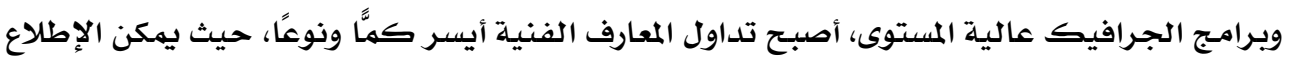

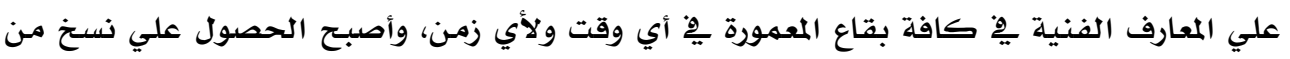

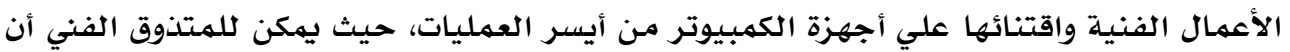

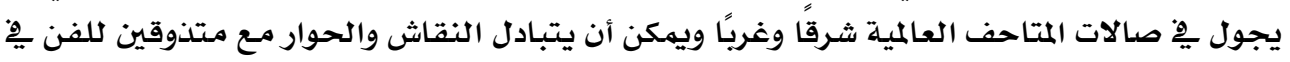

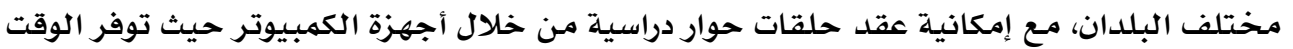

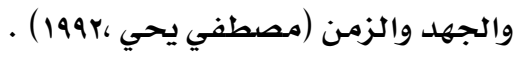

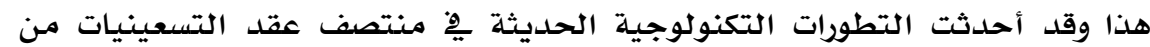

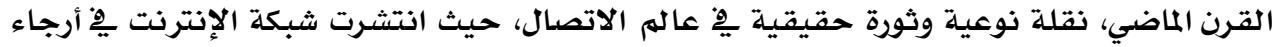

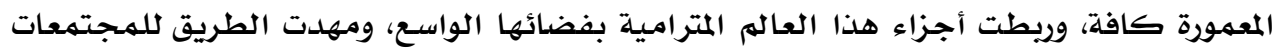

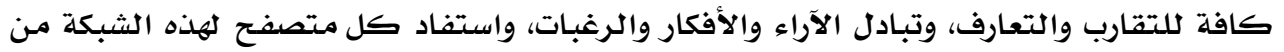

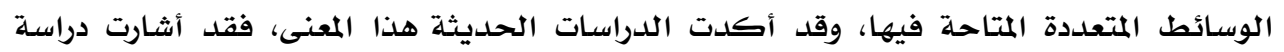

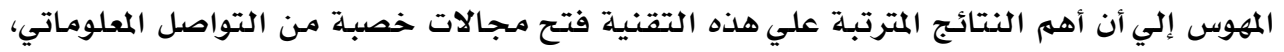


وظهر لدينا مفهوم القرية الكونية الصغيرة التي تختفي فيها عناصر الزمان والمكان والمسافات

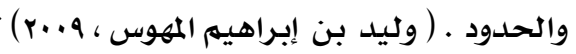

وفعلت شبكة الإنترنت نقلة نوعية ِِّ العلاقات والتفاعلات الاجتماعية، حيث تعد دراسلة

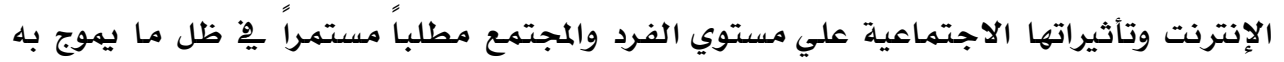

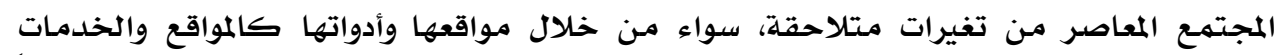

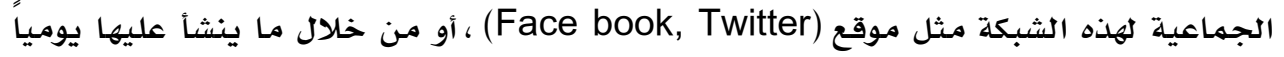

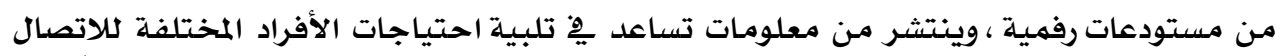

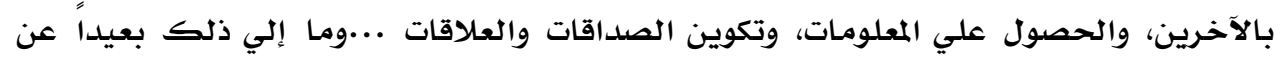

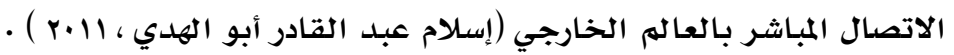

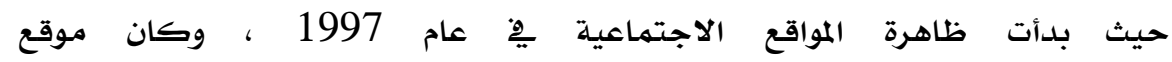

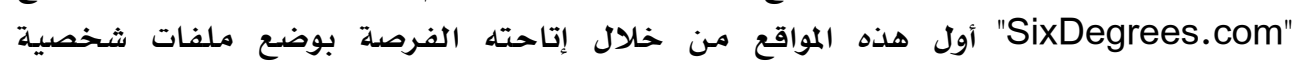

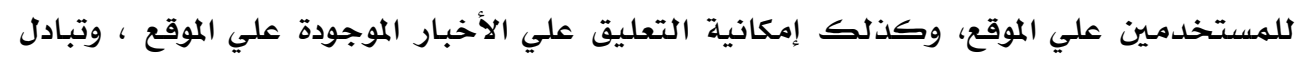

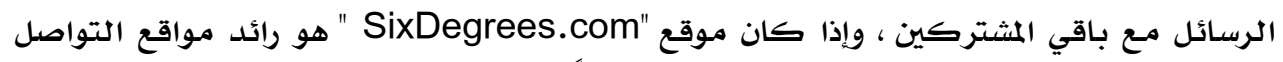

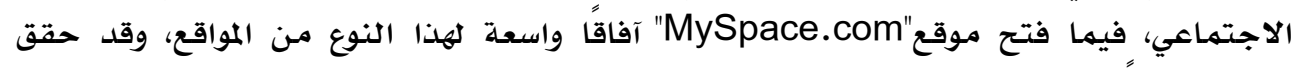

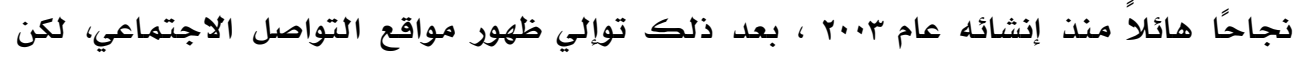

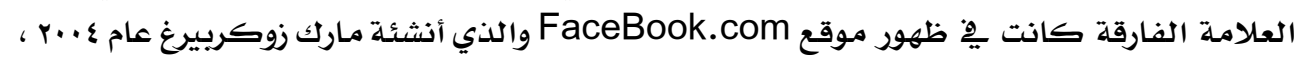

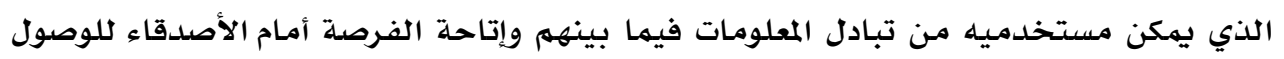

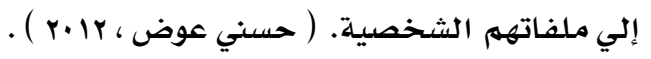
وبما أن مواقع التواصل الاجتماعي أسهمت يِّ تفعيل المشاركة لتحقق رغبة كل فئة

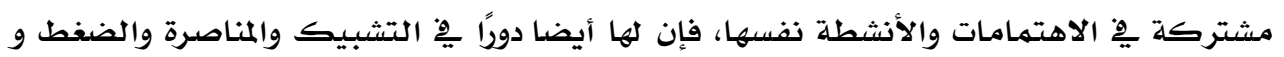

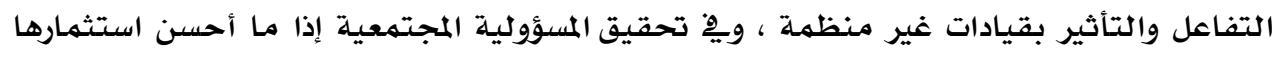

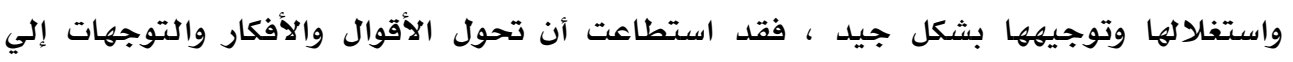

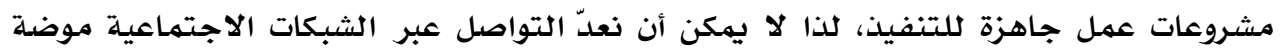

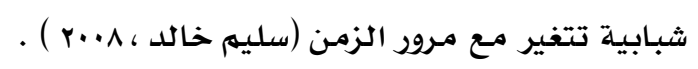

وقد أجري فيتاك وون ولامب ووش وأليسون ( Vitak,Wohn, Lampe, Wash \& ) Ellison, 2011

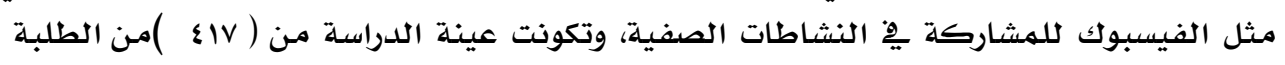

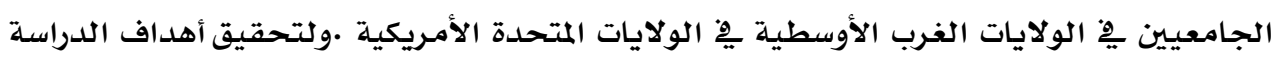

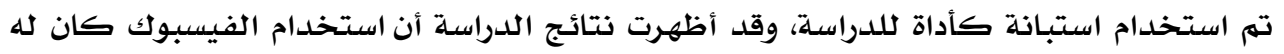

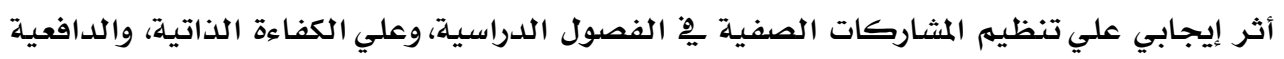

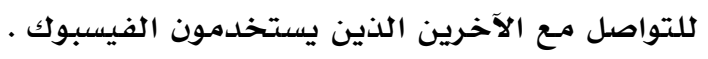


مجلة بحوث التربية النوعية - علد

وهناك الكثير من تجارب الدول يِّ استخدام الانترنت يِّ التعليم بشكل رسمي ممنهج فعلي

سبيل المثال :

\section{التجربة الإمهاراتية:}

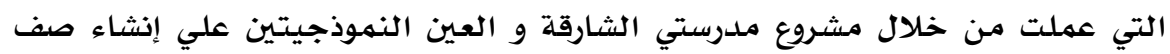

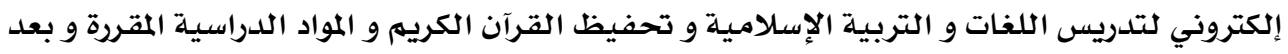

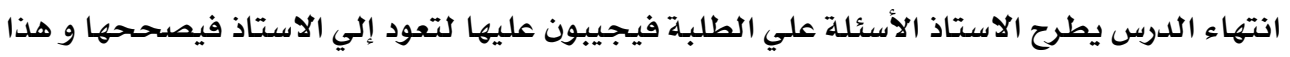

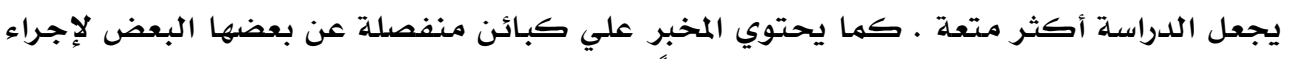

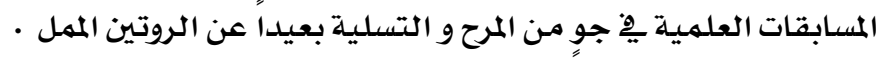

\section{التجربة السعودية:}

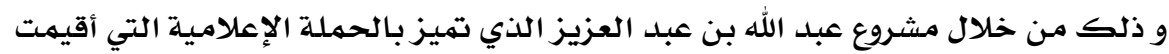

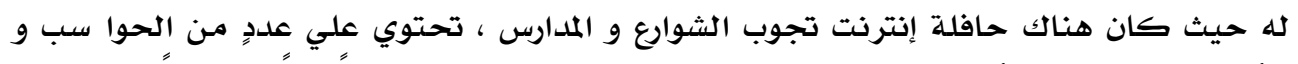

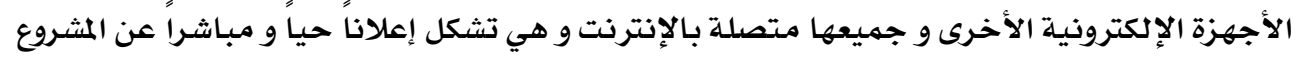

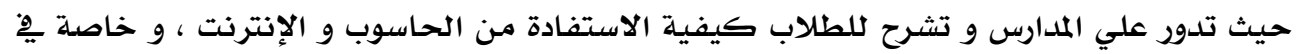

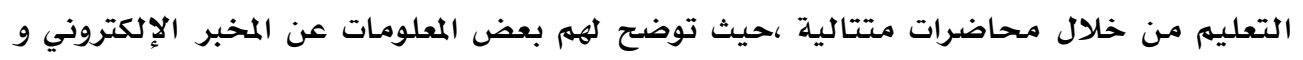

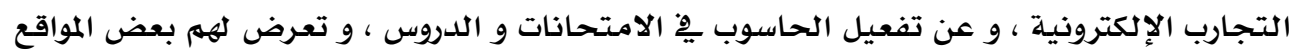

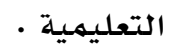

و يعمل هذا المشروع علي توظيف تقنيات الحاسب و الاتصالات يِّ العملية التعليمية مـع الاستخدام الإيجابي لها.

فهو نظام متكامل من جميع النواحي يتحدث عن كيفية بناء الجيل الإلكتروني، حيث

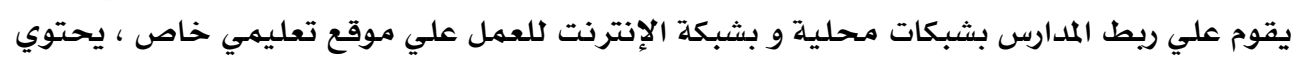

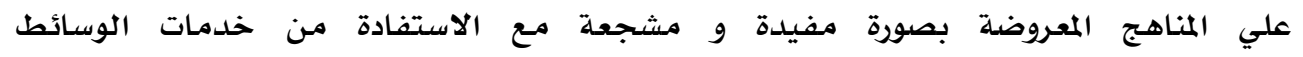

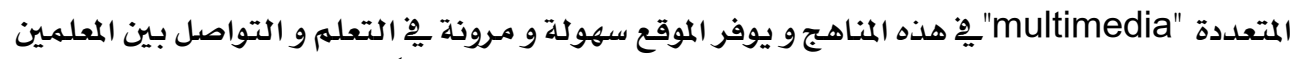

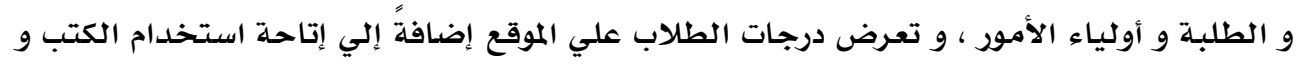

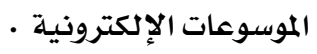

\section{التبربة الكندية:}

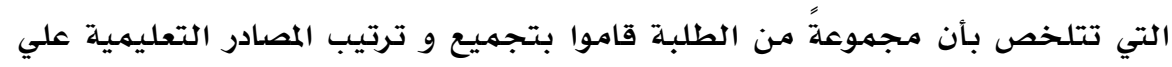

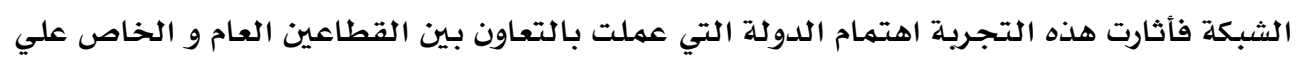

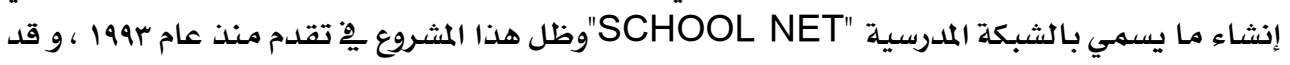

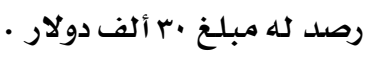




\section{التجربة الماليزية هشروع المدرسة الذكية :}

وهو مشروع شبـه متكامل ، يعمل علي إعداد جيل المستقبل باستخدام أدوات التعليه

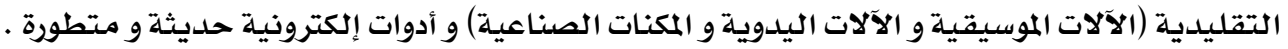

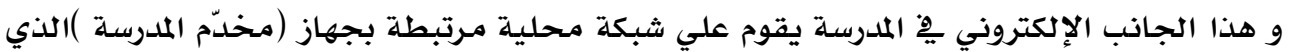

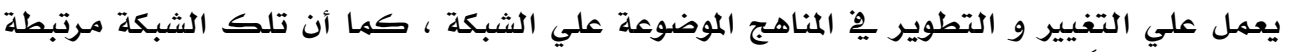

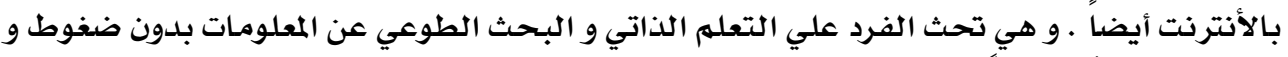

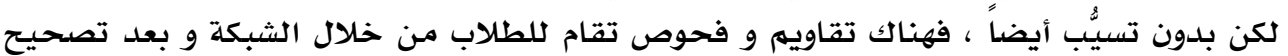

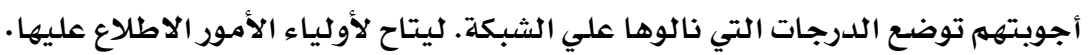

My brushes , Live sketch , Hand paint , Animal stamper : , Art of Glow , Kids/Crafts , My Coloring book hd, Learn to draw Lite , Draw Free for iPad, Draw board, Draw Crayola color studio hd, Paper Cutting for kids, kid paint, Touch Paint Free , Art Studio-draw, paint and edit photo

وتأتي هذه التجارب لعدة عوامل ومببر ات وايجابيات حيث يذكرها (حمدي الصباغ وآخـرون

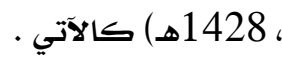

\section{هبررات استخدام الإنتزنت Internet في التعهيم}

هنالك عوامل رئيسية لاستخدام الإنترنت يِّ التعليم و هي:

1 ـ الحصول علي معلومات من مختلف أنحاء العالم.

r. تساعد علي التعليهم التعاوني الجماعي (نظراً لكثرة المعلومات المتوفرة عبر الإنترنت، فأنه

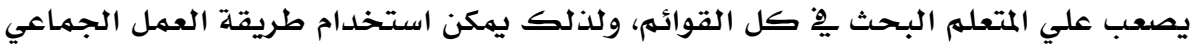

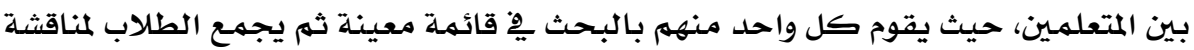

$$
\text { ما تم التوصل إليه). }
$$

r.تساعد علي الاتصال بالعالم يِّ أسرع وقت، و اقل تكلفة

ع ـ تساعد علي توفير أكثر من طريقة ِِِ التدريس ، وذلك أنها بمثابة مكتبة كبيرة تتوفر فيها

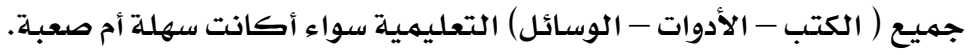

ه. تحافظ علي الفروق الفردية بين المتعلمـين، فيوجد بها برامـج تعليمية لمختلف المستويات و المتدرجـة يِّوالخطوات. 


\section{إيجابيات استخدام Internet في التعليم.}

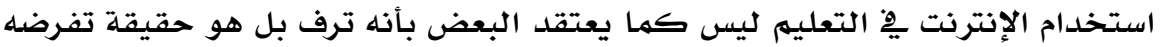

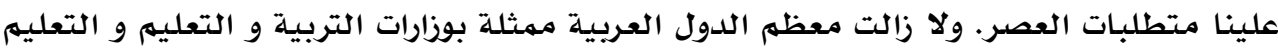

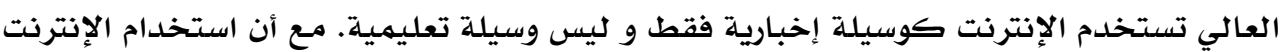

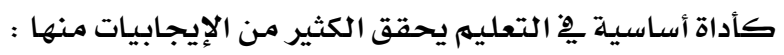
ا ـ المرونة يِّ الزمان و المكان.

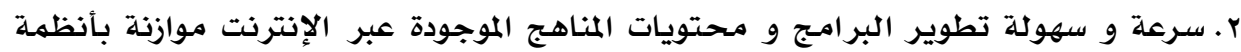

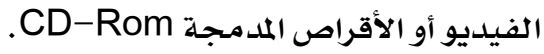
r. عـرعة الحصول علي المعلومات. ع ـ قلة التكلفة المادية موازنة باستخدام الأقمار الصناعية، ومحسطات المعات التلفزيون والراد.

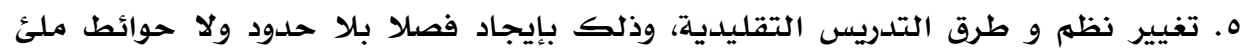

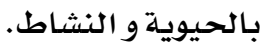

1. إعطاء التعليه صفة العالمية و الخروج من الأطر المحلية.

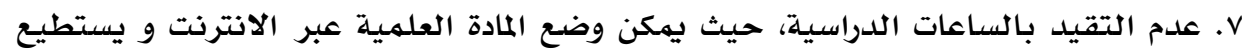
المتعلمون الحصول عليها يِّ أي وقت وأي مكان.

^. سرعة التعليم، فالوقت المخصص للبحث عن موضوع معين يكون قليل موازنة بالطرق مكان التقليديية.

9. مشاركة العلماء و الباحثين و المفكرين بِّ القضايا العلمية المختلفة ِِِ أبي وقت.

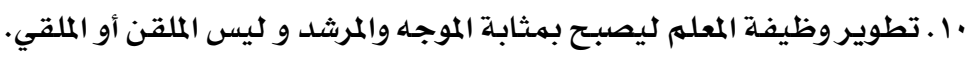
ا 1ا ـ مساعدة المتعلمين علي تكوين علاقات عالمية.

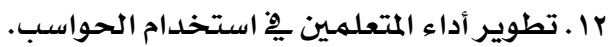

ونتيجة لهذه المبررات وكثرة استخدام الإنترنت التي آدت إلي ظهور وتطور أشكال جديدة

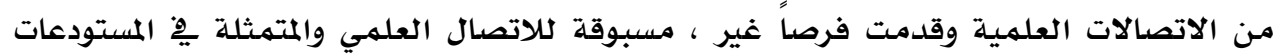

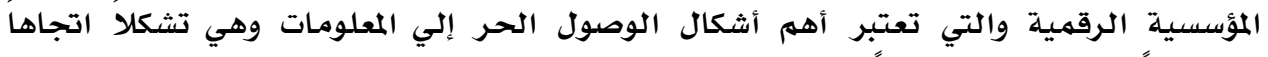

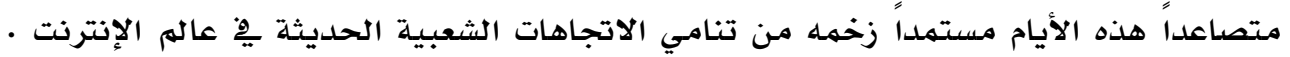

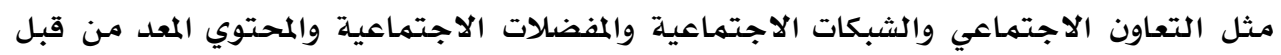

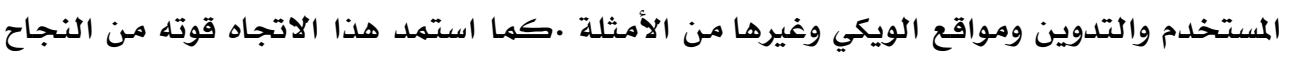

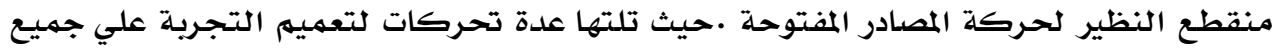

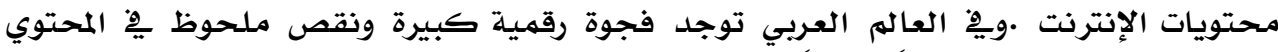

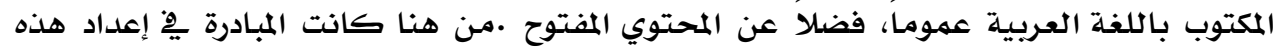

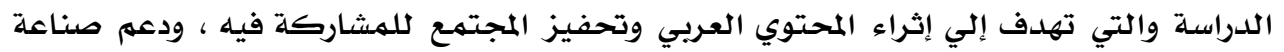

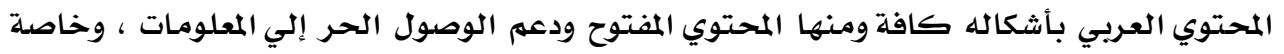


فيما يتهثل بـالمستودعات الرقمية المؤسسية والتي تهثل مستقبلاً واعدا للنشر العربي (حنان أحمد فرج ، بr.

ووفقاً لما قال (Chan \& Costa, 2005) فالمستودعات المؤسسية توفر فرصاً مثيرة

للهمجتهـ العلهي يِ البلدان النامية لنشر أبحاثهم علي الإنترنت، والاطلاع عليها والاستفادة منها يخ أي مكان يخ العالم • واستخدام المستودعات المؤسسية الرقمية لمعايير Metadata لتمكين المستخدمـين مـن البحث عن المواد المناسبـة تهكن كثيراً من الجـامعات والكليات علي مستوي العالم

$$
\text { هِّ البدء بالوصول الحر إلي ذلك الإنتاج }
$$

واستخدامـه لتقاسهم الموارد بعضها مـع بعض ، سواء داخل المؤسسة أو خارجها .وتقاسهم

الموارد بهذه الطريقة يهكن أن يؤدي إل ي تحسين نوعية البحوث والتعليهم ، وتبادل الممارسـات الجيدة وزيادة التناسق، وتعزيز الإحساس بالانتماء للمجتمع ( Barker \& lames . 2004 ) .

والمستودعات المؤسسية الرقمية تأخذ نصيب الأسد من جميع أشكال مصسادر الوصول

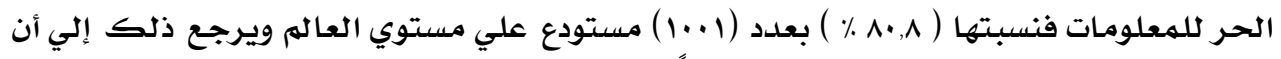

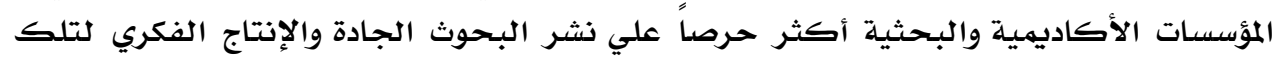
المؤسسات ، بهدف التعريف بتلك المؤسسات والاستفادة من الأبحاث المنشورة والتبادل والمثاركة بين الباحثين .

\section{فوائد المستودعات الإمسسية الرقميبة:}

ا. المستودعات الرقمية نموذج جديد وهائل للنشر العلهي ، يسهل الوصول إلي الإنتاج الفكري للمؤسسـات ومـراكز البحوث، ويٍ الوقت نفسه تشكل جزءا مـن نظام عالمي للهستودعات، وتعدل مـن النموذج التقليدي القديم للنشر العلمي يِ المجلات الأكاديمية.

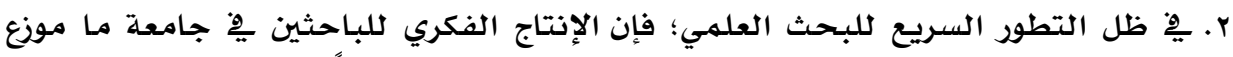
ومنشور علي الآلاف مـن المجلات الأكاديمية، وينعكس هذا إيجابيا علي الجامعات المضيفة. ץ. الإنتاج الفكري الأكاديهي بمثابـة مؤشرات ذات مغزي عن جودة المؤسسة العلمية الأكاديهية، وتزايد مركزها ، ولذلك فزيادة النشر فِ تلك المستودعات المؤسسية، وهذا

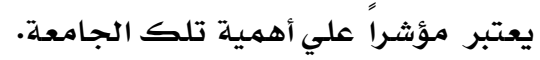

ع. قللت زيادة أسعار الاشترات يِ الدوريات من جمهور المستفيدين منها وحدت من اشتراتك

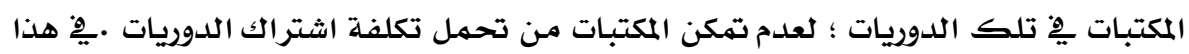
السياق ظهرت أهمية وجود نماذج بـديلة للنشر العلمي مثل المستودعات الرقمية يخ كسر احتكارات الناشرين وزيادة الوعي لدي الباحثين بزيـادة نهو الإنتاج الفكري الواضتح علي نحو متزايد. ويمكن للمستودعات المؤسسية تأدية هذه الوظيفة سواء تنفيذها يِ احِ الجامعات بصفة فردية أو ِِ مشاريـع تعاونيـة. 


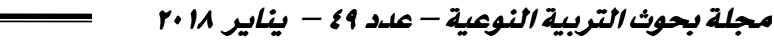

ه. تقدم المستودعات إمكانية كبيرة للباحثين للاطلاع علي الدراسات المماثلة ِِّ تخصصله ،

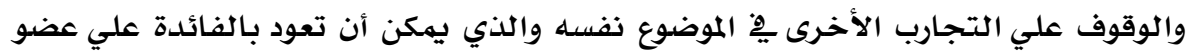
هيئة التدريس. T. القدرة علي تقييم الإنتاج المنشور لعضو هيئة التدريس علي أساس الكيف وليس الكمر، ينبغي أن يعود بالفائدة علي الباحثين والمؤسسات الأكادئ المباديمية.

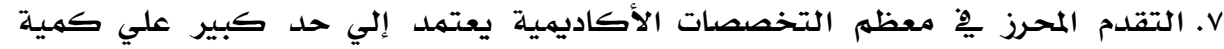

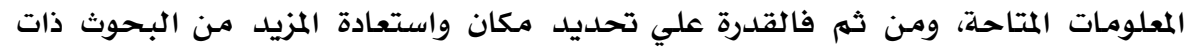

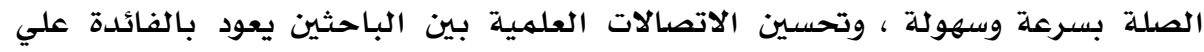

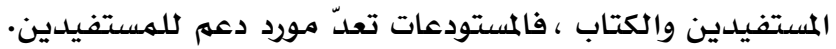

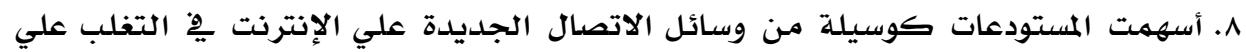

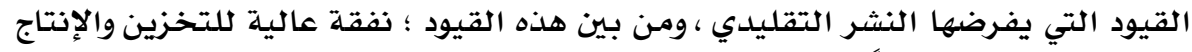

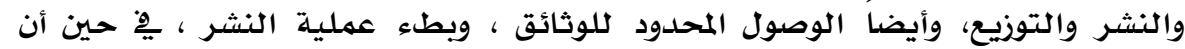

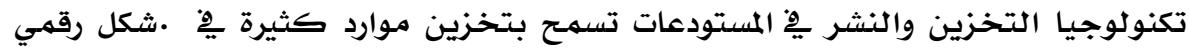

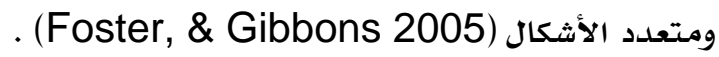

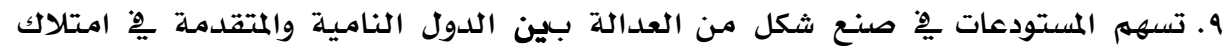

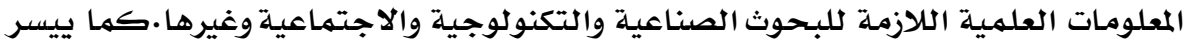

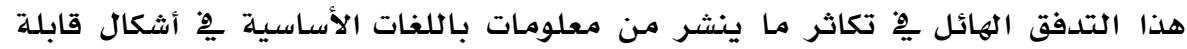

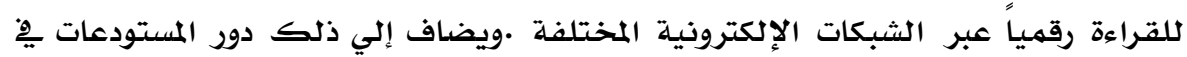

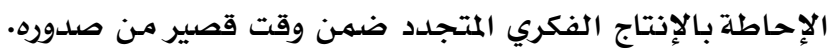

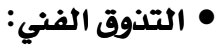
هو استشعار وتقدير القيم الجمالية والفنية والتعبيرية للأعمال الفنية ، والتجاوب

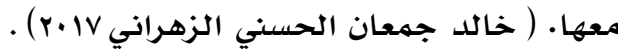

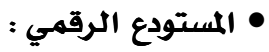

هو عبارة عن قاعدة بيانات متاحة علي الشبكة العنكبوتية، تشتهمل علي الإنتاج الفكري

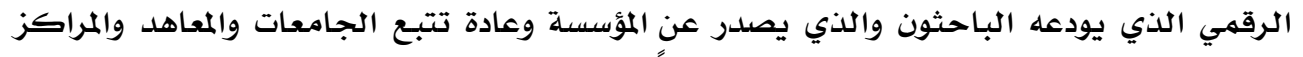

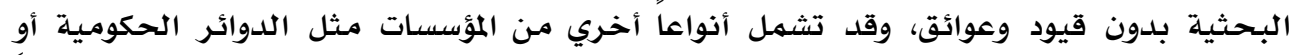

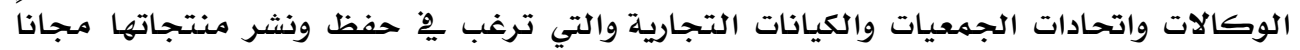

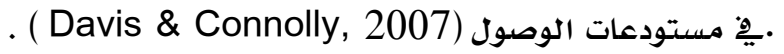


الشبكات الاجتماعية هي مواقع ويب تسهـح لمستخدميها بإنشاء صفحات ومساحات

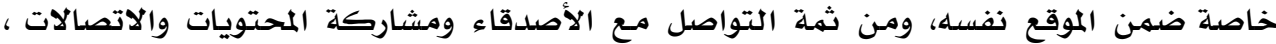

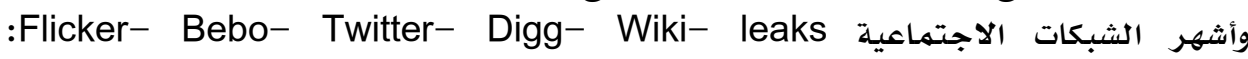
.Face book - Tumbler - Google - MySpace- YouTube- Linkedln Wikipedia

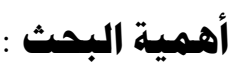

وتكمـن أهميـة البحــث الحسالي يِّ تنميــة التواصـل المجتمعـي بــين الطالبــات والمسؤولين التربويين .

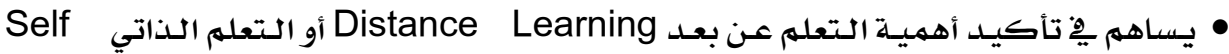
Learning

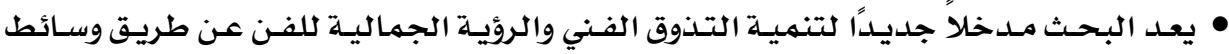
تعليمية غير تقليدية.

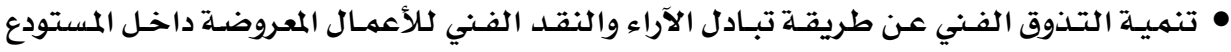

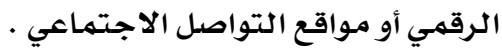

• معرفة أثر برامج التواصل الاجتماعي والمستودعات الرقمية علي الانترنت لتنمية التذوق الفني

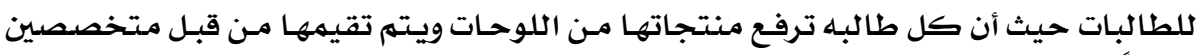

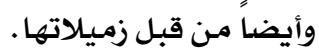

• عمل أرشيف للورث الفنية المعطاة للطالبـات ( مكتبـة فيديو اليكترونيه علي موقع يوتيوب ) . • تخزين نسخة من الأعمال الفنية للطالبـات بصورة رقميـة بحيث يسهل الرجـوع اليها وتقيمها

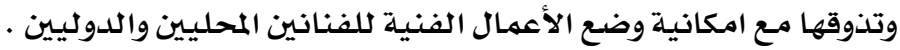

تم تطبيـق البحـث علـي طالبـات الـصف التاسـع بمدرسـة مسشرف المتوسـطة للبنـات بـالإدارة

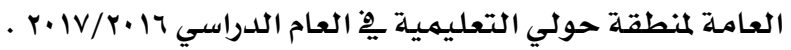




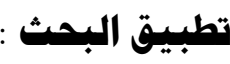

تم تطبيق هذا البحث عن طريق ثلاث محاور رئيسية .

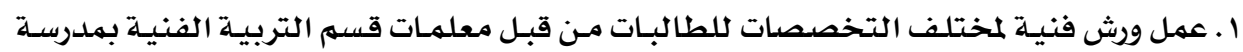

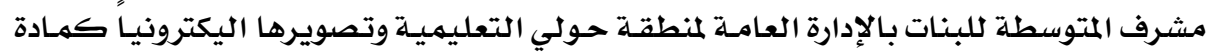

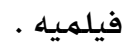
r. عمـل ورثــة عن فن الكاريكـاتير للأسـتاذ يوسـف بـن سـيف وتعليهـه عن طريـق الجهاز اللـوحي

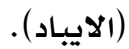

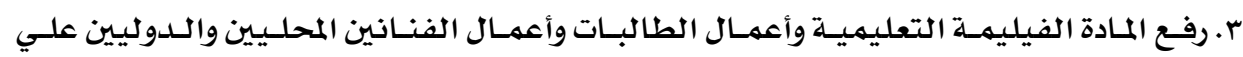

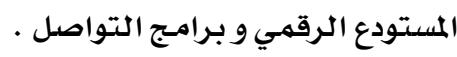

\section{الدراسات السابقة :}

دراسة خالد جمعان الحسني الزهراني (Y.lV) هدفت هذه الدراسـة إلي التعرف علي أثر

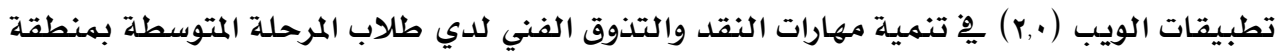

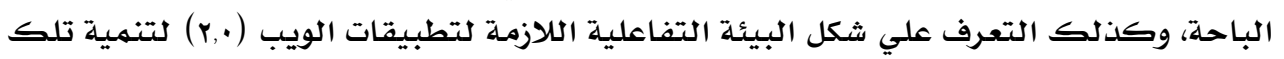

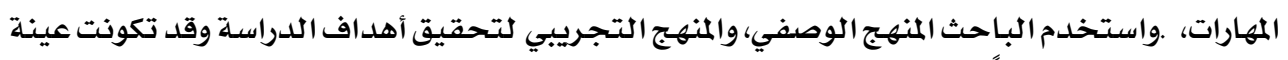

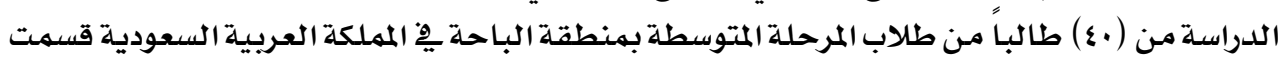

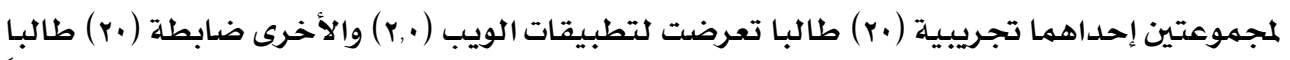

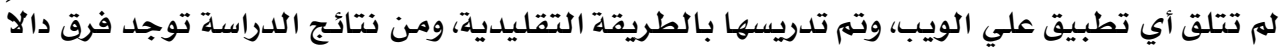

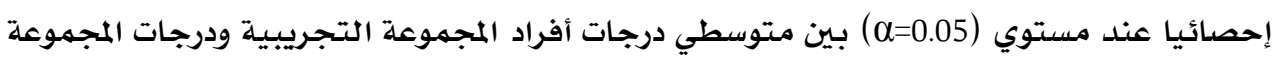

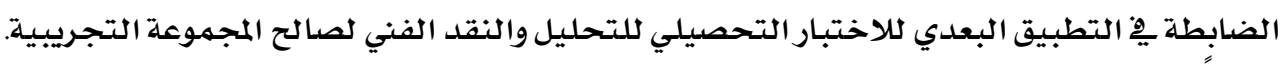

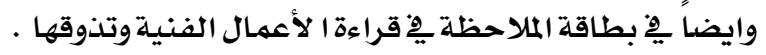

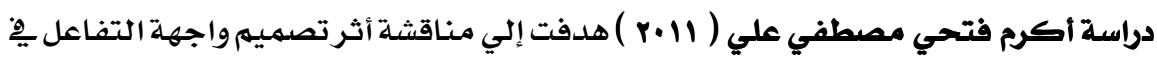

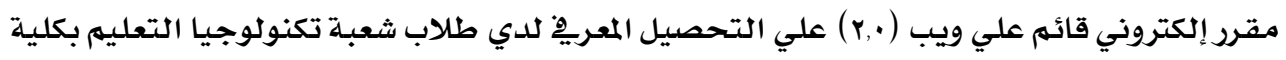

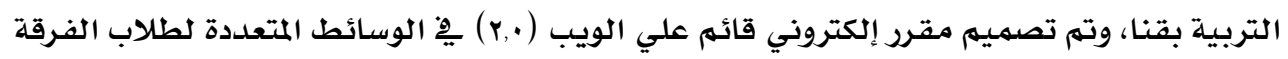

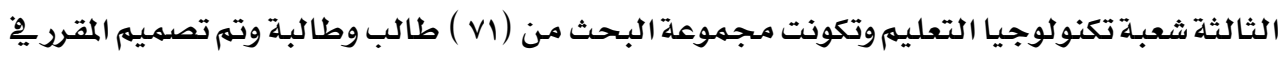

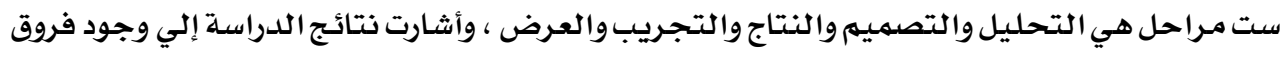

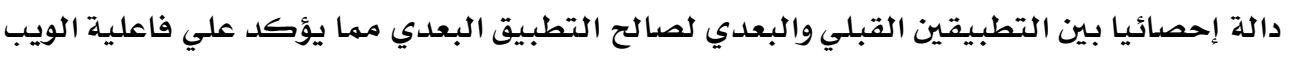

$$
\text { (r.•) }
$$

دراسة سيكوندو وآخرون (2009) Secundo وقد هدفت إلي التعرف علي كيفية تصميم

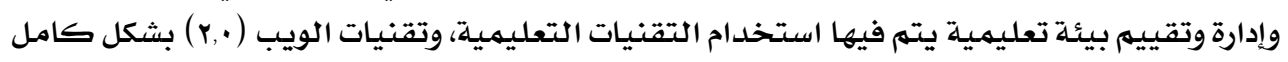

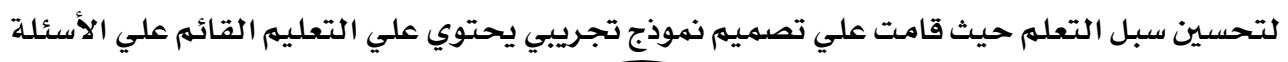


والاعتماد علي أدوات التعلهم مثل (الويكي،المدونات) وخلصت الدراسة إلي أن تقنيات الويب (·.ب) لها

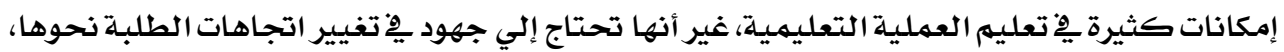
وإتقان مهارات التفاعل معها.

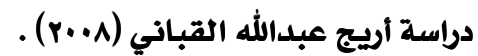

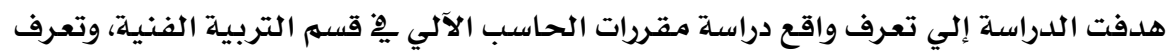

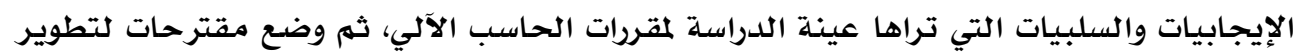

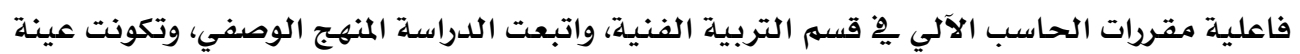

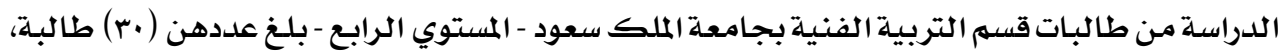

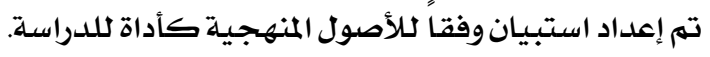
وأظهرت نتائج الدراسة أن استخدام الحاسب الآلي يفتح مجالات جديدة لهم تكن مستخدمـة

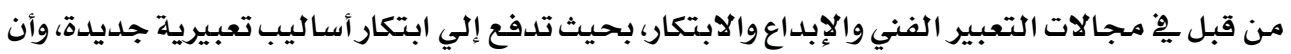

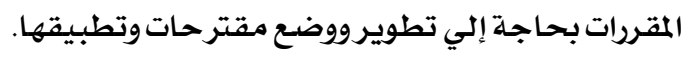

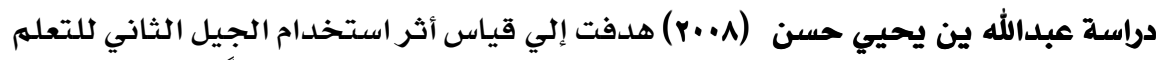

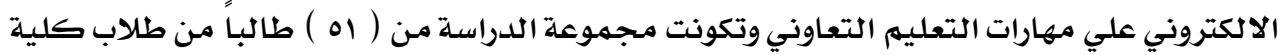

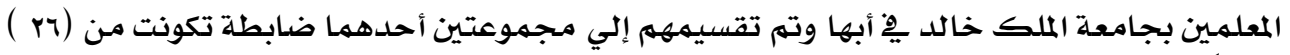

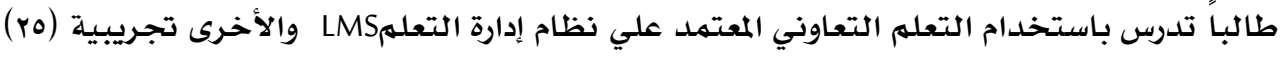

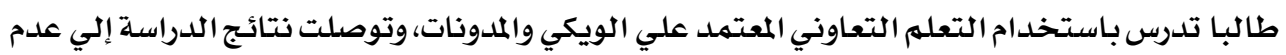
وجود فروق ذات دلالة إحصائية بين المجموعتين. دراسة كاستانيدا Castaneda (2007) هدفت إلي معرفة أثر استخدام أدوات الإنترنت

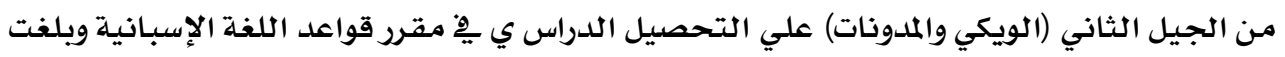

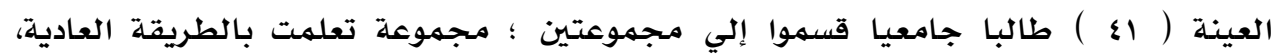

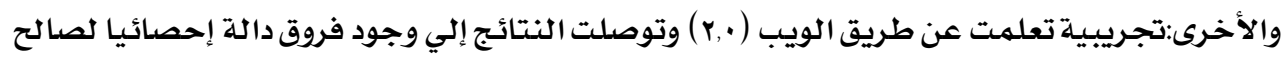

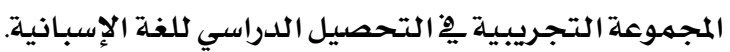

دراسة برسباتش Perschbach (2006) هدفت إلي معرفة أثر انعكاس تفكير الطالب من خلال استخدام التعلم التعاوني المعتمد علي المدونات، وتكونت العينة من (67) طالب وطالب وطالبة؛

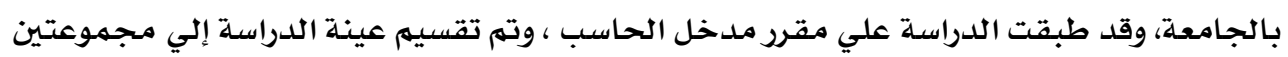

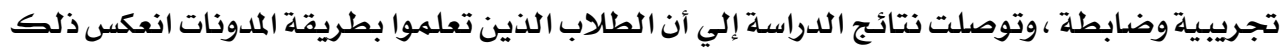

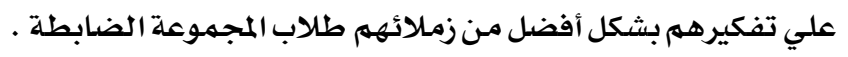

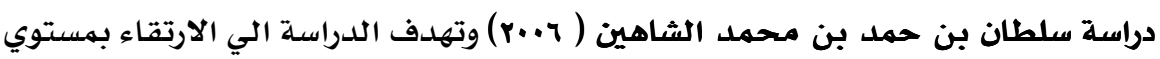

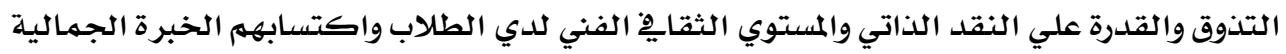

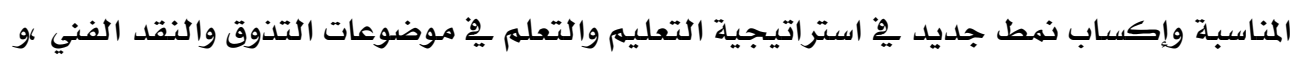

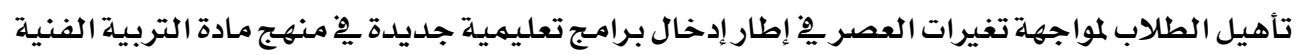




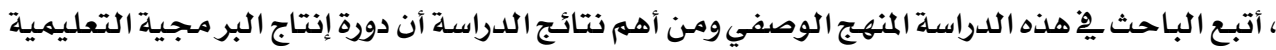

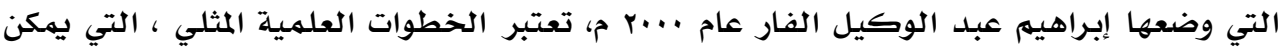

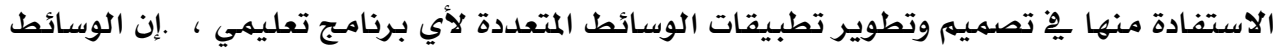

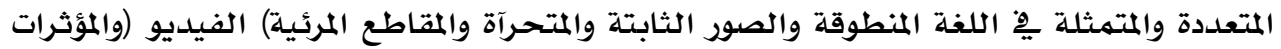

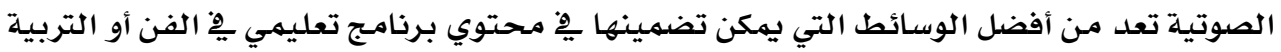

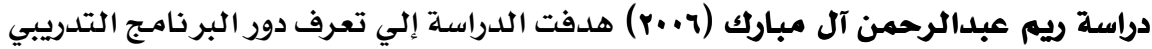

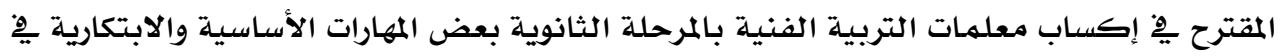

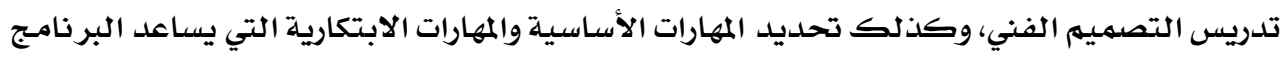

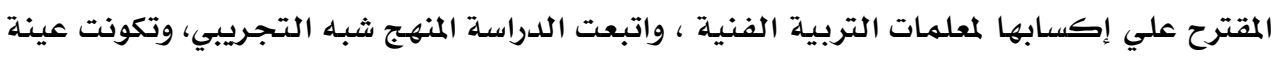

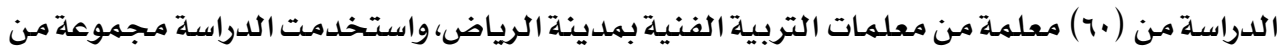

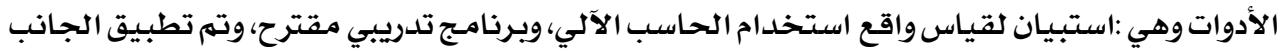

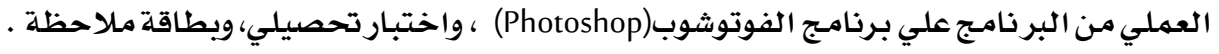
وأسفرت نتائج الدراسـة عن أن نموذج التصميهم المقترح من قبل الباحثة مناسب لتصميهم

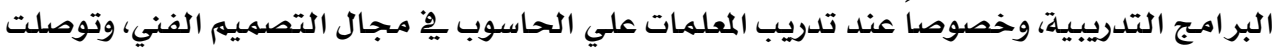

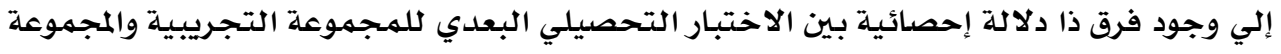

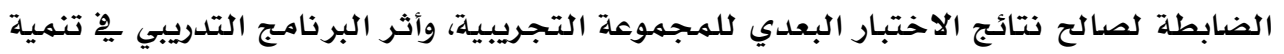
الابتكار لدي المعلمات.

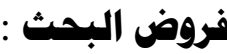

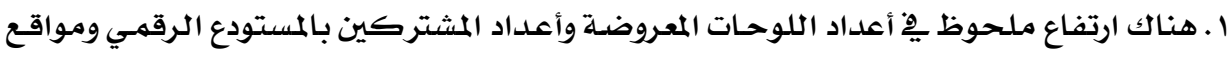

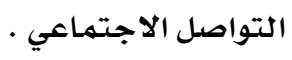

r ـ هناك تنامي للمستوي الفني الأعمال الفنية . 
صور هن تطبيق البحث

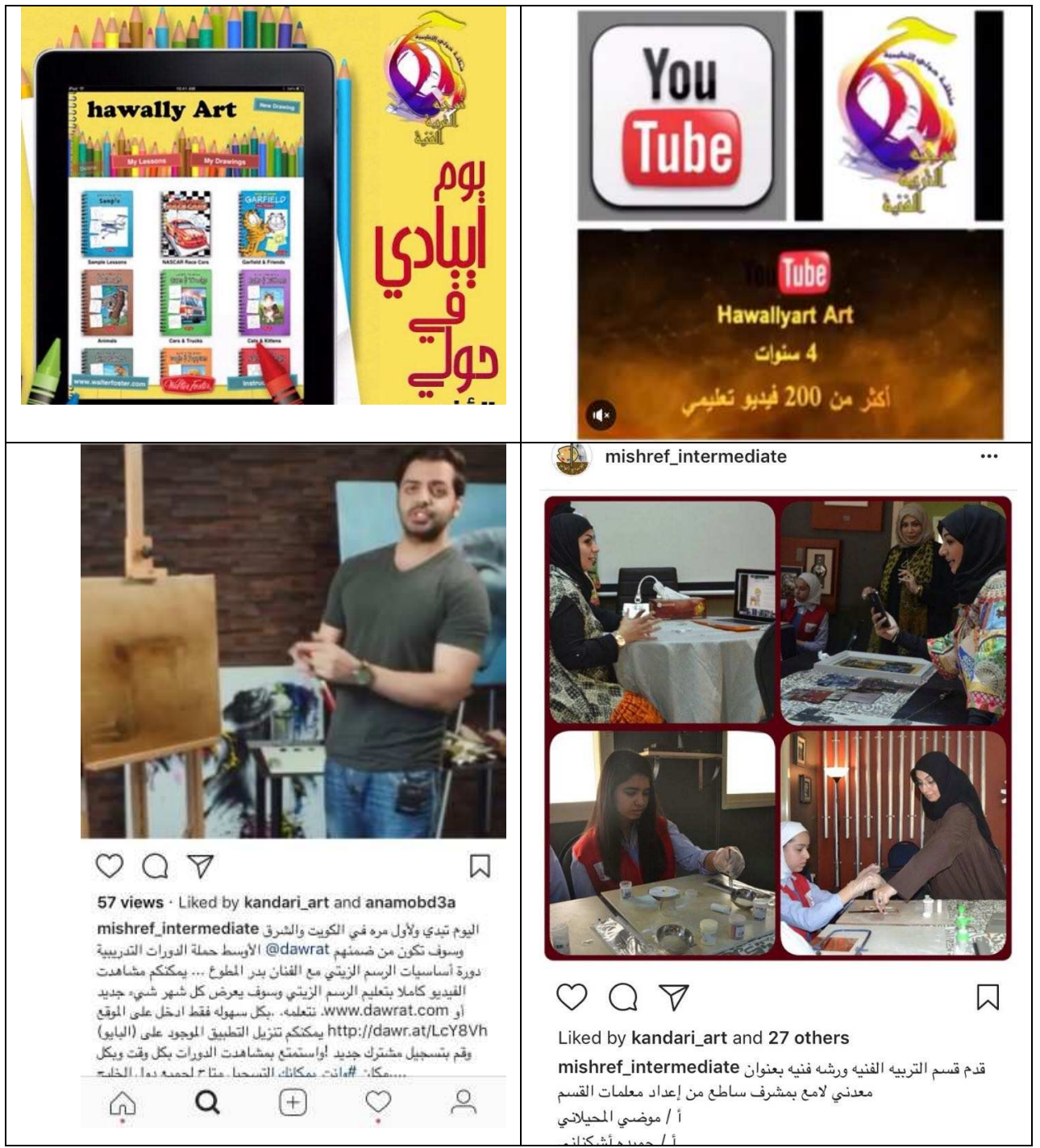




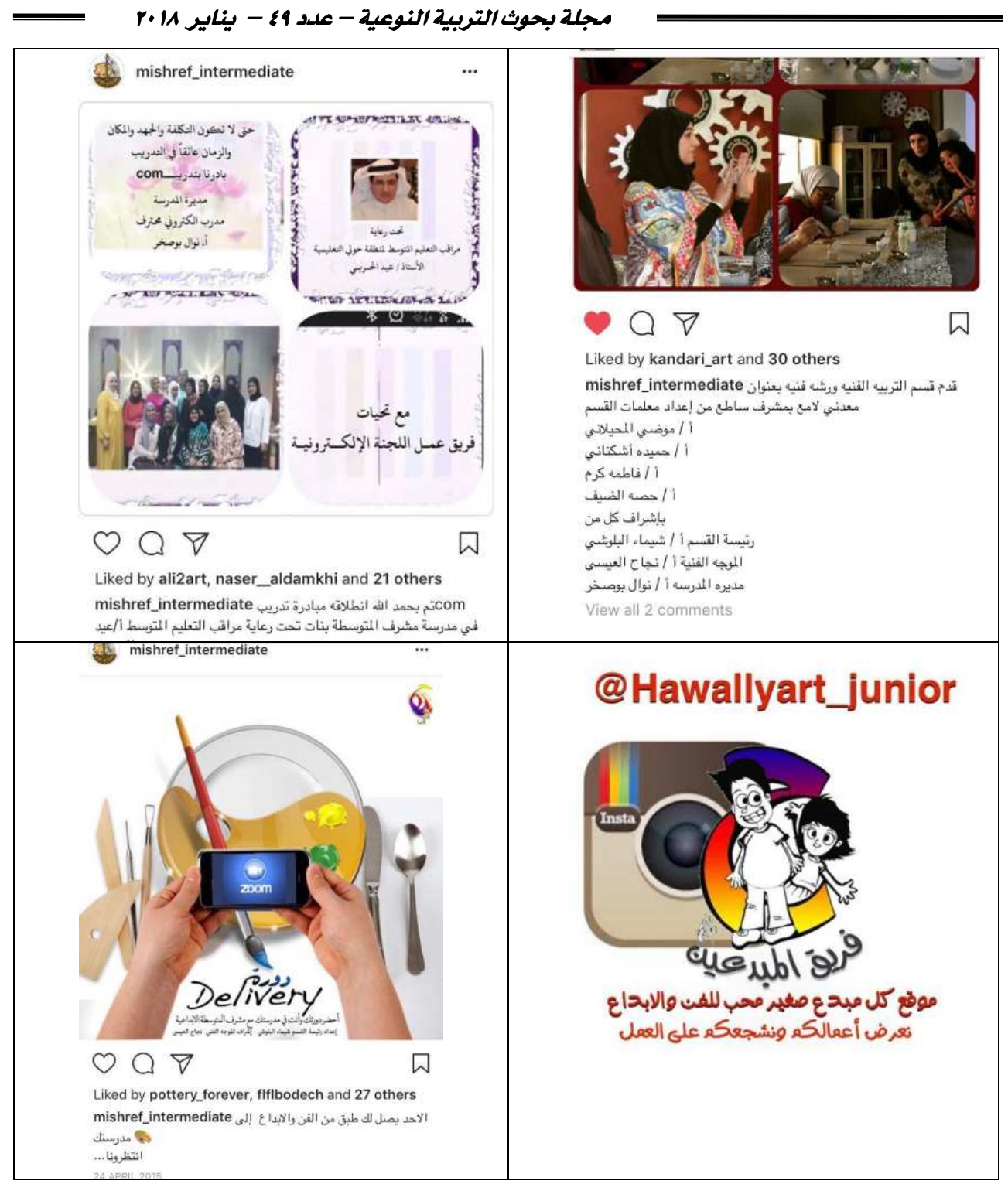




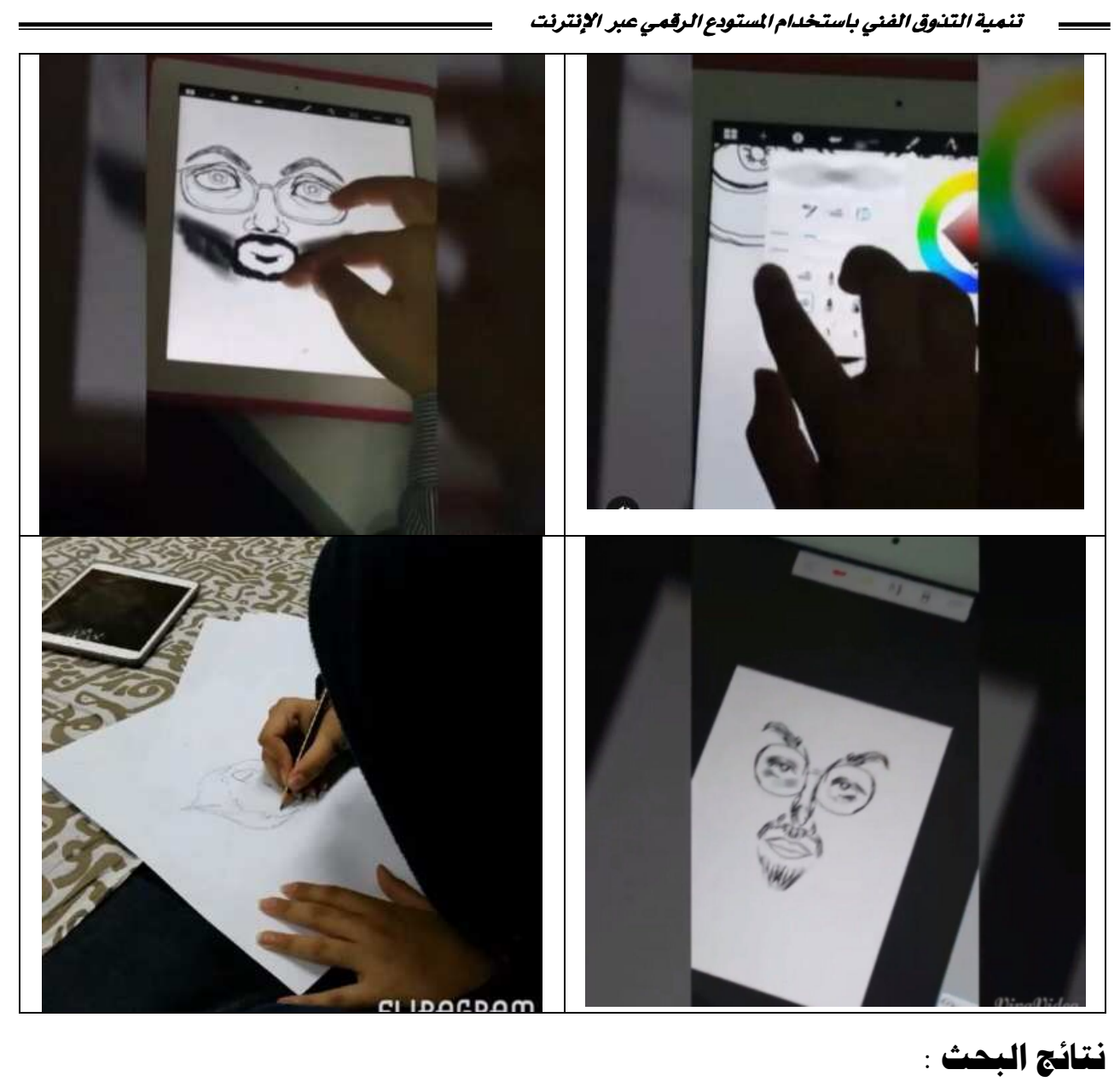

وكانت نتائج البحث كالتالي ارتفاع المستوي الفني للوحات المعروضدة ، تزايد أعداد اللوحات المعروضة بنسب ملحوظة ، تزايد الاقبال من الفنانين المعروفين والموجهين ومتخصصي التربية يِّ زيارة هذه المواقع وأبداء الرأي يِّ اللوحات المعروضلة .

المراجع المربئ

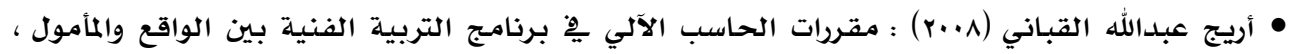

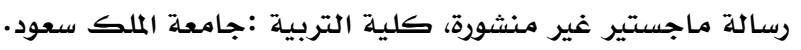

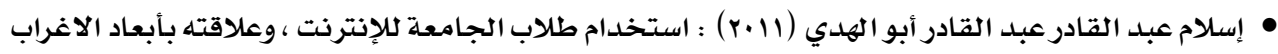

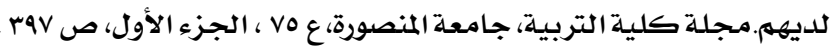




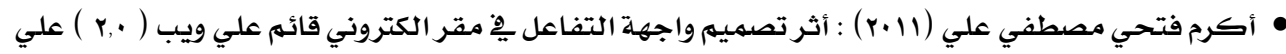

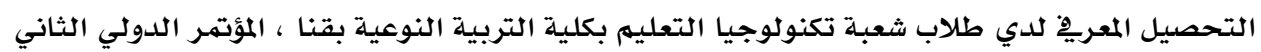

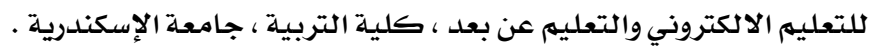

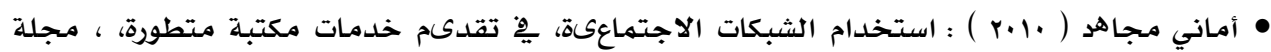

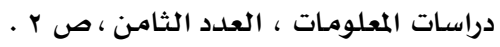

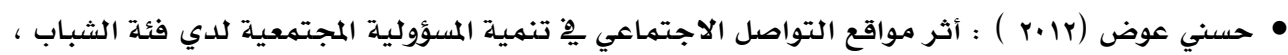

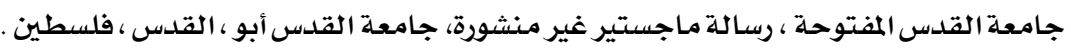

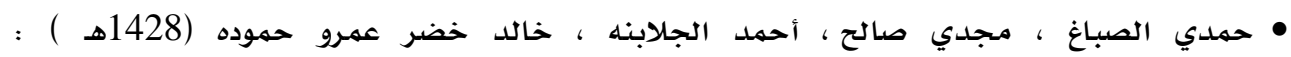

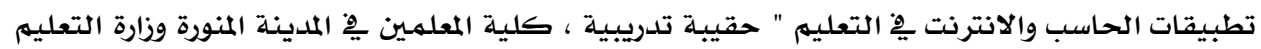
العالي ، المملكة العربية السعودية .

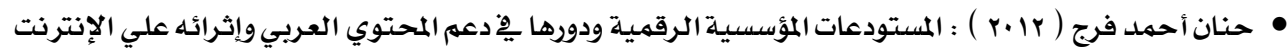

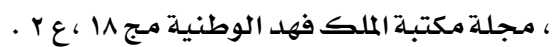

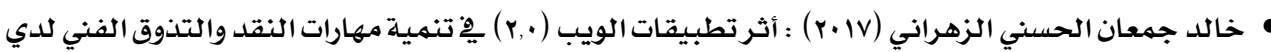

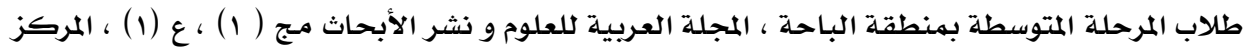
القومي للبحوث ، دولة فلسطين.

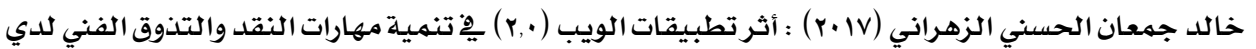

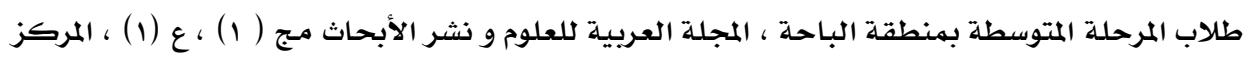
القومي للبحوث ، دولة فلسطين.

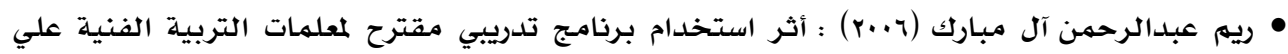

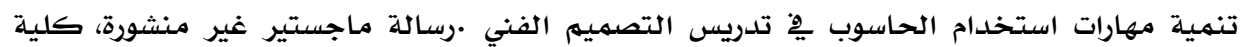
التربية :جامعة الملك سعود.

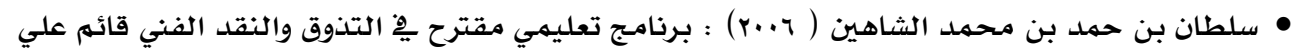

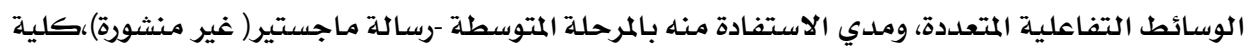

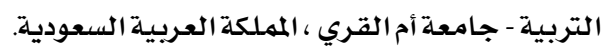

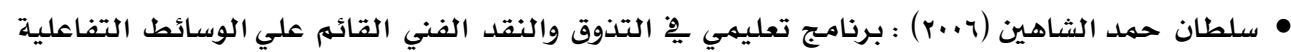

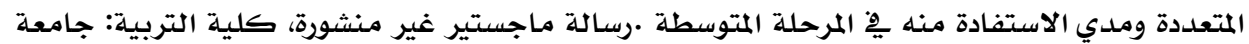

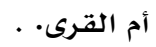

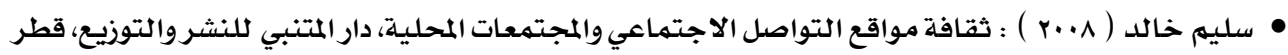
، صه.

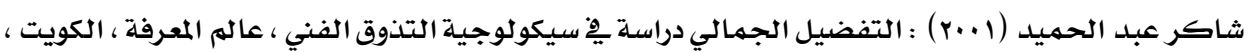
ص VA.

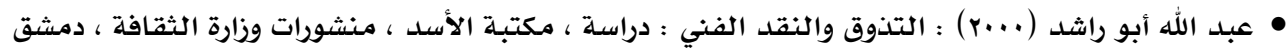
، الجمهورية العربية السورية ، ص الهو 9. 


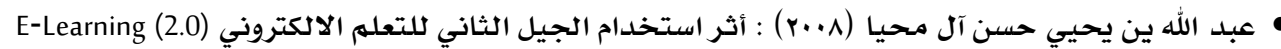

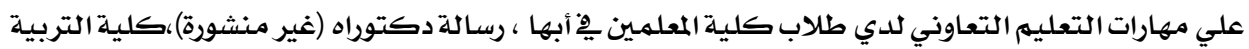

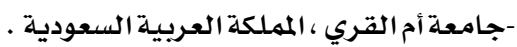

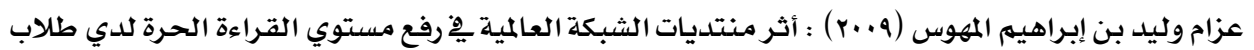

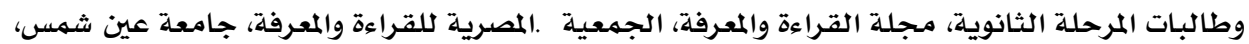

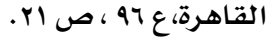

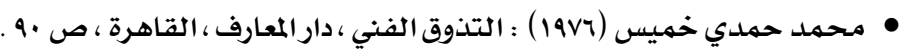

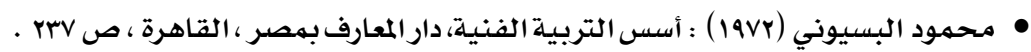

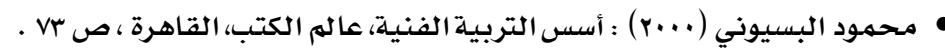

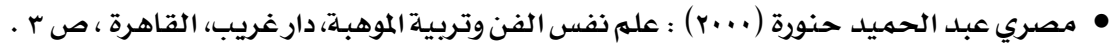

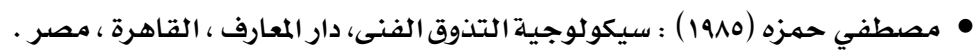

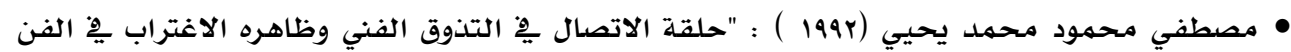

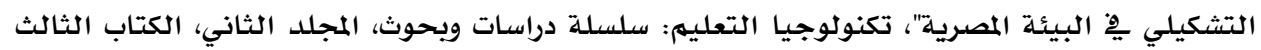

صواr.

• مصطفي محمود محمد يحيي (199r) : حلقة الاتصال بِّ التذوق الفني ظاهرة الاغتراب ِِّ الفن التشكيلي

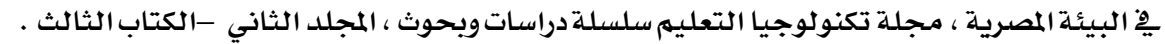

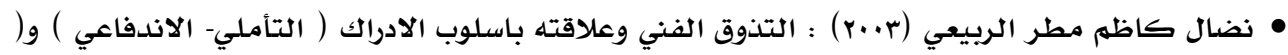

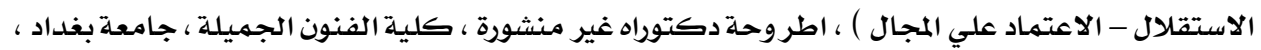
العراق ، ص ^ץ .

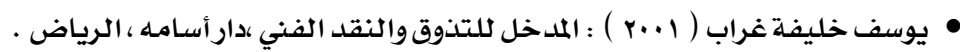

- Barker , E \& Iames ,H. \& Knight , G .( 2004) Long-Term retention Reuse of Elearning obiect and materials, Roport commissioned by the JISC . available: www.jisc.ac.uklupload_documents/ .

- Castaneda, Vise, Daniel (2007): The Effects of Wiki-and Blog technologies on the Students' Performance When Learning the Preterit and Imperfect Aspects in Spanish. (Dissertation submitted to the College of Human Resources and Education at West Virginia University in partial fulfillment of the requirements for the degree of Doctor of Education in Technology Education).

- Chan,Leslie . \&Costa , Sely. amd (2005) Participation in the global knowledge commen ; challengs and opportunities for research dissemination in developing countries. New Library World , No3-4 . p.106 . Available: http//www.emeraldinsight,com . 
- Davis , P.M. , \&Connolly, M.J (2007) Institutional repositories: evaluating the reasons for non-use of cornell University,s installation of DSpace, D-Lip Magazine, Vol.13, No.3/4.http://www.webcitation.org/dlip/ .

- Foster, N.F., \&Gibbons S. (2005) Understanding faculty to improve content recruitment for institutional repositories, D-Lib Magazine, Vol. 11, No. 1 http;//www.dlip.org/dlip/january05/foster/01foster.html1 .

- Perschbach Jane W. (2006) : Blogging: An Inquiry into The Efficacy of a Webbased Technology for Student Reflection in Community College Computer Science Programs, University College of Engineering and Computing, Nova Southeastern University, USA. .

- Secundo, G., Elia, G., Del Vecchio, P, (2009) Sustaining Tunisian SMEs' Competitiveness and Innovation in the Digital Economy submitted to the International Journal of Technology and Globalisation (IJTG) - Special Issue on: "Emerging Markets" submitted on 31th July 2009

- Vitak, J., Whon, D., Lampe, C., Wash, R., Ellison, N. (2011). Student use of Facebook for organizing collaborative Student use of Facebook for organizing collaborative. Computer-Supported Collaborative Learning, 6: 329-347.

- Wani ,Z. A. \& Gul, S. \& Rah, J.A (2009) Open access repositories : Aglobal perspective with an emphasis on Asia , Chinses Librarienship ; an International Electronic Journal , No.27. Available : http://www. Iclc.us/clieg/c127WGR.htm. 


\section{Online Digital Repository And Its Role In The Development Of Artistic Appreciation} Abeer Abdullah Alkandari*

\section{Abstract}

Cloud Computing System like other technologies contain pros and cons, but in the field of education will be a basic extension of e-learning, especially mobile education and widespread education, and perhaps the only challenge that should be overcome is the comprehensive coverage of the rapid access to the Internet, and can be said that the cloud computerized including the Software, communication tools and data is the ideal solution for many educational problems. Popular social networking applications such as Instagram, WhatsApp, and Facebook are one of the most prominent ways to create an active digital cloud open to all, accessible from Anywhere and anytime. Since the technical taste is a process of communication, and the process of communication requires the presence of two parties, one is the sender or creator and the other is the receiver, and between them a channel of communication and a message on this channel, where the sources of communication are diverse and many methods and methods are many.

The importance of the current research lies in the development of social communication between female students and educators.

- Helps to emphasize the importance of distance learning or self learning, which has become the current trend in universities both globally and locally.

- Research is a new entrance to the development of artistic taste and aesthetic vision of art through non-traditional educational media.

The aim of the research is to find out the impact of social networking programs and digital repositories on the Internet to develop the artistic taste of female students and develop the artistic taste of female students as each student uploads their products from the paintings and is

* Assistant Professor of Psychology - Umm Al-Qura University 
evaluated by specialists and also by her colleagues. It also aims to create a digital archive in which all students register their works Non-deleteable.

Research Sample The research was applied to the students of the ninth grade in the school of Musharraf medium for girls in the General Administration of the area of education in the academic year 2016/2017.

The most important results of the research were the high level of the paintings displayed, the increase in the number of paintings displayed in a remarkable proportion, the increasing popularity of well-known artists, guides and specialists of education to visit these sites and express opinion in the paintings displayed.

Keywords: digital warehouse, social networking programs, artistic Appreciation.. 